\title{
Novel cork-polymer composites reinforced with short natural coconut fibres: Effect of fibre loading and coupling agent addition
}

\author{
Emanuel M. Fernandes*, Vitor M. Correlo, João F. Mano, Rui L. Reis \\ 3B's Research Group - Biomaterials, Biodegradables and Biomimetics, University of Minho, Headquarters of the European Institute of Excellence on Tissue Engineering \\ and Regenerative Medicine, AvePark, 4806-909 Taipas, Guimarães, Portugal \\ ICVS/3B's - PT Government Associate Laboratory, Braga/Guimarães, Portugal
}

\section{A R T I C L E I N F O}

\section{Article history:}

Received 14 November 2012

Received in revised form 28 January 2013

Accepted 31 January 2013

Available online 10 February 2013

\section{Keywords:}

A. Polymer-matrix composites (PMCs)

A. Hybrid composites

B. Mechanical properties

E. Extrusion

Cork

\begin{abstract}
A B S T R A C T
Composites from high density polyethylene filled with cork powder and coconut short fibres, in two different ratios, were prepared in a twin-screw extruder followed by compression moulding process. The main motivation of this work was to improve the mechanical performance without compromising the use of high weight percentage of natural component used in the preparation of cork-based composites. The morphology of the hybrid composites were more homogeneous in the presence of the coupling agent (CA) displaying enhanced fibre-matrix adhesion. Moreover, the use of CA based on maleic anhydride promotes a mechanical reinforcement effect on the tensile properties, including the elongation at break. The addition of coconut fibre resulted on an increase of $27 \%$ in elastic modulus and $47 \%$ in the tensile strength when compared with the unreinforced cork-based (50-50) wt.\% composite. This work clearly shows that the addition of $10 \mathrm{wt} . \%$ of short-coconut fibres, randomly distributed, can be effectively used as reinforcing strategy of cork-based composite materials, preferably in the presence of $2 \mathrm{wt}$.\% of CA.
\end{abstract}

(c) 2013 Elsevier Ltd. All rights reserved.

\section{Introduction}

Government regulations and a growing environmental consciousness throughout the world have generated a paradigm to move in the direction of designing materials compatible with the environment [1]. Over the past two decades, natural fibres have received considerable attention as a substitute for synthetic fibre reinforcements in polymeric materials. Natural fibres are increasingly used for reinforcement in thermoplastics over traditional reinforcing materials such as glass fibres and particle minerals (e.g. talc, $\mathrm{CaCO}_{3}$ and mica) due to their low cost, lightweight, good thermal and acoustic insulation, acceptable specific strength, reduced tool wear, corrosion resistance, availability, renewable resource and recycling possible with lower environment impact $[2,3]$, promoting the concept of sustainability. As a result of these advantages some of the plant fibre based thermoplastic composites have already found applications in furniture manufacture, nonstructural building applications and as interiors parts in automotive industry [4-6]. Cork is the suberous covering tissue of the species Quercus Suber L., commonly known as the cork oak and the

\footnotetext{
* Corresponding author. Address: 3B's Research Group - Biomaterials, Biodegradables and Biomimetics, University of Minho, AvePark, Zona Industrial da Gandra, 4806-909 Caldas das Taipas, Portugal. Tel.: +351 253 510900; fax: +351 253 510909.

E-mail address: efernandes@dep.uminho.pt (E.M. Fernandes).
}

unique properties arise from the closed cell structure [7,8]. During the last years there has been an increasing interest concerning cork based materials and its potential to be used in composite applications $[5,9,10]$. However, natural materials are inherently incompatible with hydrophobic thermoplastics such as polyolefins reducing the mechanical performance. Major limitations of using natural materials as reinforcements in such matrices include poor interfacial adhesion between polar-hydrophilic fibre and nonpolarhydrophobic matrix, and difficulties in mixing due to poor wetting of the fibre with the thermoplastic matrix [11]. Previous studies on cork-polymer composites (CPCs) have demonstrate that increasing the cork content the tensile mechanical properties are compromised and reduced [12,13]. Reinforcement strategies of cork composites, such as the use of low amounts of coupling agent (CA) [14], or the use of conventional chemical modification methods of the natural component [15], can be applied to improve the compatibility and interfacial bonding between polymeric matrix and dispersed component. The motivation of this work was to prepare high performance cork based composites, in order to support tensile stresses developed in complex geometries or when submitted to finishing operations such as lamination, by using natural fibres preferably in combination with a CA. Additionally, studies involving hybrid bio-fibre systems containing cork powder through melt based technologies have not been addressed so far. Therefore composites comprising these two kinds of natural materials (e.g. cork and coconut fibre) may exhibit the desirable 
properties of the individual constituents. Coconut fibre, or coir, is a versatile lignocellulosic fibre obtained from coconut trees (Cocos nucifera), which grow extensively in tropical countries. Sri Lanka and India are considered to be the major coir fibre producers in the world. Coconut fibres may be decomposed in $20-30$ years in the nature, and it may be regarded as an environmentally friendly material [16]. Chemical composition [7,17-20] of both natural materials is presented in Table 1 . Coconut fibres as already been used to reinforce polyolefins [4,21-23]. Both coconut fibres and cork are used as insulator material in thermal and acoustic applications $[24,25]$ and presents lower hydrophilic behaviour when compared with sisal fibre [26]. In this study, high density polyethylene (HDPE) was selected as the matrix to develop the hybrid corkbased composites because: HDPE presents a good balance property range, is easy to process through melt based technologies, such as extrusion and compression moulding, and is a high consumption industrial polymer that presents low price in the market which is of significant importance to the 'cost-performance' assessment. Additionally, it requires a relatively low processing temperature, which is essential because of the relatively low thermal stability of both natural components. In this work, we report the effect of using coconut fibre as a reinforcement material, preferably in the presence of $2 \mathrm{wt}$.\% of CA, to promote higher mechanical performance of the cork-based composites.

\section{Materials and methods}

\subsection{Natural materials}

Cork sanding powder, with particle size $<500 \mu \mathrm{m}$ and specific weight of $157 \pm 2 \mathrm{~kg} \mathrm{~m}^{-3}$ and a humidity of $\sim 5.4 \%$ was collected at the Amorim Revestimentos S.A. (S. Paio Oleiros, Portugal) industrial facilities. The brown coconut fibre from Hayleys Exports PLC (Kotugoda, Srí Lanka) presented a diameter of $277.4 \pm 38.8 \mu \mathrm{m}$, a humidity of $8.2 \%$ and specific weight of $845.1 \pm 46.6 \mathrm{~kg} \mathrm{~m}^{-3}$, was collected at Amorim Isolamentos S.A. (Vendas Novas, Portugal).

\subsection{Polymer materials and coupling agent}

A commercially available polyethylene (HMA - 025), HDPE,

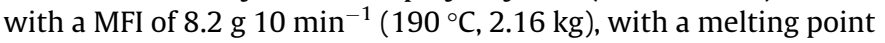
of $132.5^{\circ} \mathrm{C}$ from ExxonMobil (Germany) was supplied by Pallmann Maschinenfabrik GmbH \& Co. (Germany) in the powder form with particle size between $125 \mu \mathrm{m}$ and $1500 \mu \mathrm{m}$. The used coupling agent, a HDPE functionalized with maleic anhydride (PE-g-MA), containing $0.5-1.0 \mathrm{wt} . \%$ of maleic anhydride, was Exxelor PE 1040 , with MFI of $1.4 \mathrm{~g} 10 \mathrm{~min}^{-1}\left(190^{\circ} \mathrm{C}, 2.16 \mathrm{~kg}\right)$, and a melting point of $131.3^{\circ} \mathrm{C}$, from ExxonMobil (Germany).

\subsection{Fibre diameter and density}

The diameter measurements of coconut fibres were made in five spaced locations along the gauge length of 30 different specimens using an optical microscope Olympus BH-2 (Tokyo, Japan) equipped with an Olympus DP11 (Japan) digital camera. A histogram for the coconut fibre was performed and a normal distribution to characterize the coconut fibre diameter. Regarding cork powder, the particle size was determined used an analytical sieve
(Retsch. AS 200, Germany) after a sieving period of 5 min at a medium amplitude. The density of the coconut fibres and of the hybrid cork based composites were determined according to the standard ASTM D 792, using an analytical balance equipped with a stationary support for the immersion vessel using liquid propanol.

\subsection{Composites processing}

Before compounding all natural raw materials were pre-dried at $80^{\circ} \mathrm{C}$ during $24 \mathrm{~h}$ to stabilise the cork and the coconut fibres in terms of moisture content. The moisture content, determined by oven-dry weight before processing, was found to be $1.5-3 \%$. The prepared compositions and processing conditions are summarized in Table 2. The compounding was performed in a counter-rotating twin-screw extrusion machine (Carvex, Portugal), which had a screw diameter of $52 \mathrm{~mm}$ and an L/D ratio of 18 with a nonintermeshing, mixing mode screw configuration. The barrel temperature was in the range $130-160^{\circ} \mathrm{C}$, and the screw speed was fixed at $30 \mathrm{rpm}$. The cork powder and the grinding HDPE were premixed and manually feed in the hopper system with the cut coconut fibres. No extrusion head was used in order to minimize the residence time and shear heat dissipation. The extruded material was cooled in air, granulated in a cutting mill to produce the composite pellets with dimensions $\leqslant 7 \mathrm{~mm}$. In a further step, the obtained pellets were compression moulded using a hydraulic press (Moore, UK) to produce boards with $186 \times 118 \mathrm{~mm}^{2}$ and $3 \mathrm{~mm}$ of thickness from the different compositions. The mould temperature was $150{ }^{\circ} \mathrm{C}$ and the material was kept $8 \mathrm{~min}$ in the mould without pressure followed by 2 min under pressure of $1.42 \mathrm{MPa}$. Tensile bars in dog bone shape were obtained from these boards using a computer numerical control CNC machine (Roland 3D Plotter MDX-20, UK). The cut hybrid composites present a compact aspect, not evidencing present macroscopic pores or voids. The specimens were produced according to ISO 527-2. Nonetheless, its thickness is slightly higher $(3 \mathrm{~mm})$ than the standard.

\subsection{Scanning electron microscopy}

The morphology of the natural fibres and the fracture surface of the tensile tested composite specimens were analysed using a NanoSEM 200 FEI (The Netherlands) scanning electron microscope (SEM). Before being analysed all the specimens were coated by ion sputtering with an Au/Pd alloy (80-20 wt.\%) in a high resolution sputter coater of Cressington 208HR (Watford, UK).

\subsection{Mechanical properties}

Tensile properties of the bundle coconut fibres were measured with a Instron 4505 Universal Machine, (USA) using a $1 \mathrm{kN}$ load cell, a crosshead speed of $1 \mathrm{~mm} \mathrm{~min}{ }^{-1}$, and a fibre gauge length of $30 \mathrm{~mm}$. Prior to testing, fibres were mounted on sturdy paper frames using a high-strength epoxy adhesive and placed in a desiccator for a minimum of $48 \mathrm{~h}$.

The tensile properties of the developed cork based composites reinforced with coconut fibres were determined in the same equipment according the standard ISO 527-2, using a gauge length of $20 \mathrm{~mm}$. The tensile force was taken as the maximum force in the force deformation curve. Tensile modulus was estimated from

Table 1

Chemical constituents (wt.\%) of the lignocellulosic materials used on the bio-based composites.

\begin{tabular}{|c|c|c|c|c|c|c|c|}
\hline Chemical composition (wt.\%) & Origin & Cellulose & Hemicellulose & Lignin & Suberin & Extractives & Literature reference \\
\hline Cork & Bark & & & $21-29$ & $33-45$ & $8.5-19$ & {$[7,19]$} \\
\hline Coconut fibre & Fruit & 43 & 0.3 & 45 & - & $0.35-3.13$ & {$[17,18,20]$} \\
\hline
\end{tabular}


Table 2

Processing conditions used for the studied cork composite compositions.

\begin{tabular}{|c|c|c|c|c|c|c|c|}
\hline \multirow[t]{2}{*}{ Code } & \multirow[t]{2}{*}{ Cork (wt.\%) } & \multirow[t]{2}{*}{ HDPE (wt.\%) } & \multirow[t]{2}{*}{ Coco fibre (wt.\%) } & \multirow[t]{2}{*}{ Coupling agent (wt.\%) } & \multirow[t]{2}{*}{ Natural component (wt.\%) } & \multicolumn{2}{|l|}{ Extrusion } \\
\hline & & & & & & Temperature profile $\left({ }^{\circ} \mathrm{C}\right)$ & Motor (rpm) \\
\hline CPC 1 & 50 & 50 & 0 & 0 & 50 & $130 ; 145 ; 155^{\mathrm{a}}$ & 30 \\
\hline CPC 2 & 49 & 49 & 0 & 2 & 49 & & \\
\hline $\mathrm{CPC} 3$ & 47.5 & 47.5 & 5 & 0 & 52.5 & $130 ; 150 ; 160^{\mathrm{b}}$ & 30 \\
\hline CPC 4 & 46.5 & 46.5 & 5 & 2 & 51.5 & & \\
\hline CPC 5 & 45 & 45 & 10 & 0 & 55 & & \\
\hline CPC 6 & 44 & 44 & 10 & 2 & 54 & & \\
\hline
\end{tabular}

a Temperature profile of CPC 1 and CPC 2 compositions.

b Temperature profile of CPC 3 to CPC 6 compositions.

the initial slope of the stress-strain curve (between $0.05 \%$ and $1 \%$ strain) using the linear regression method. Samples were conditioned at room temperature for at least $48 \mathrm{~h}$ before testing. A crosshead speed of $5 \mathrm{~mm} \mathrm{~min}^{-1}$ was used until rupture. The average and standard deviations were determined using eight specimens per condition. To allow for a comparison of the material property profiles in terms of the potential for reinforcement of the mechanical performance, the Ashby plots for the specific tensile modulus against the specific strength are illustrated for absolute property values with the respective standard deviations.

\subsection{Statistical analysis}

One-way analysis of variance (ANOVA) with post hoc Bonferroni multiple comparison tests was used to infer about significant
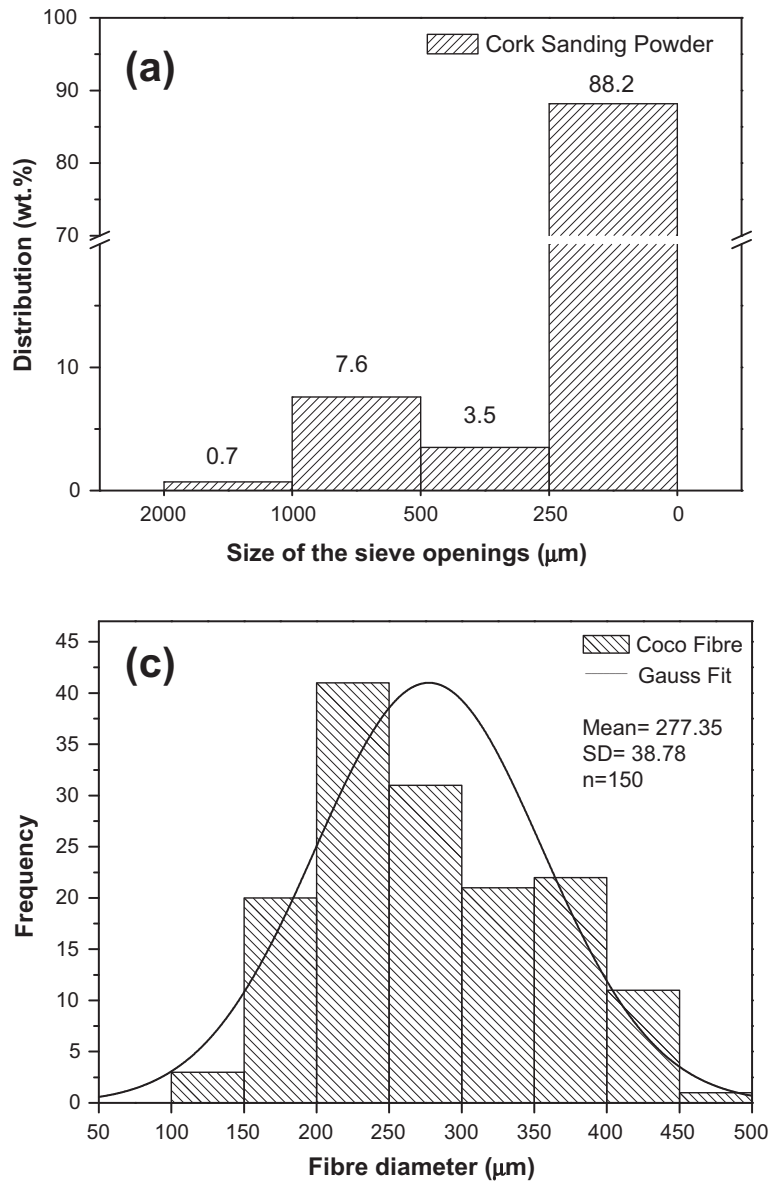

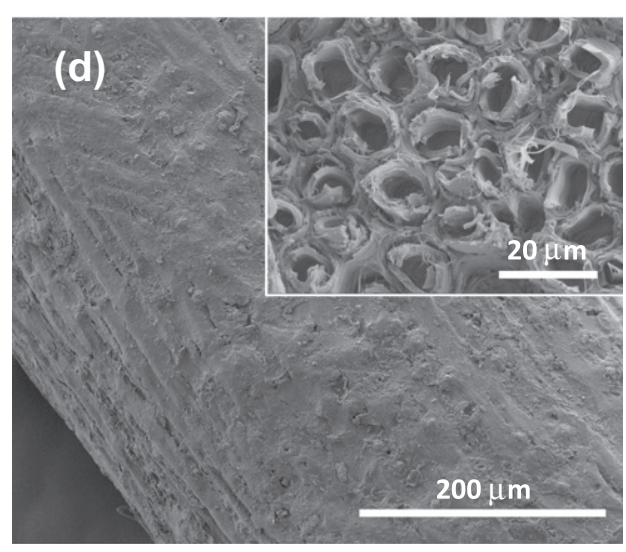

differences between mean values of the mechanical properties in the developed cork composite materials. Assumptions of ANOVA such as normality were evaluated with Shapiro-Wilk test. A level of $\alpha=0.05$ was used for statistical significance.

\section{Results and discussion}

3.1. Physical, morphological and mechanical properties of the natural component

The cork particle size distribution, the coconut fibre diameter variation and the morphology of the used natural components are reported in Fig. 1. Cork powder, obtained from the sanding process, is composed of: a high percentage (88.2 wt.\%) of particle with a size lower than $250 \mu \mathrm{m}$, a small fraction (11 wt.\%) between $1 \mathrm{~mm}$

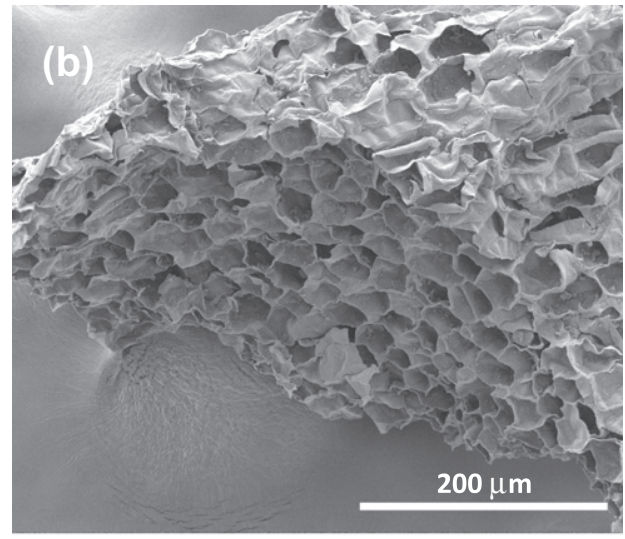

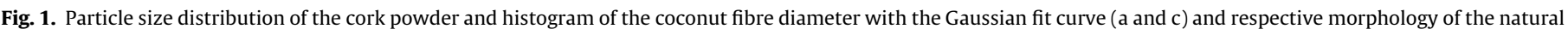
materials by scanning electron microscopy (b and d). 
Table 3

Tensile properties of coconut fibre and the polyethylene matrix and respective density and moisture content of the used components to produce the composite materials.

\begin{tabular}{|c|c|c|c|c|c|}
\hline Material & Max. strength (MPa) & Modulus (GPa) & Maximum strain (\%) & Density $\left(\mathrm{kg} / \mathrm{m}^{3}\right)$ & Moisture content (\%) \\
\hline Coconut fibre & $134.3 \pm 34.5$ & $2.16 \pm 0.62$ & $34.4 \pm 4.7$ & $845 \pm 47$ & 8.2 \\
\hline Cork & - & - & - & $165 \pm 21$ & 5.4 \\
\hline Polyethylene & $26.8 \pm 0.4$ & $0.63 \pm 0.04$ & $>200$ & $956 \pm 1$ & 0 \\
\hline
\end{tabular}

and $250 \mu \mathrm{m}$ and a residual part (less than $1 \mathrm{wt} . \%$ ) between 2 and $1 \mathrm{~mm}$ (Fig. 1a). The histogram of Fig. 1c) shows the diameter distribution of coconut fibre, with the mean value of $277.4 \mu \mathrm{m}$ and a gaussian fit distribution. The coconut fibre used to reinforce the cork-based composites presents a broad fibre diameter distribution of 71.8-465.6 $\mu \mathrm{m}$ for a confidence interval of 95\%. Cork powder presents reduced density and lower initial moisture content when compared with the coconut fibre as presented in Table 3. The determined density of the used coconut fibres is similar to the HDPE matrix, although the literature typically reports higher values of $1150 \mathrm{~kg} / \mathrm{m}^{3}$ [17] for this natural fibre. The morphological analysis revealed that cork powder presents several cells despite its reduced particle size (Fig. 1b). This anisotropic foamed material presents a close cellular structure [7] where the section of the cork particle shows preferentially the radial direction. The morphology of the coconut fibres was also analysed and the results are shown in Fig. 1d). The obtained SEM image shows a representative top surface of the coconut fibre displaying many pinholes on the surface ('rotten wood'-like appearance) [26]. The inset image presents the cross-section of the coconut fibre, which can be more or less cylindrical, containing axially oriented cells/fibrils of around $10 \mu \mathrm{m}$ diameter. These observations are in accordance with the results reported in literature $[22,26]$. The mechanical tests of the coconut fibres revealed an higher mechanical performance than the thermoplastic matrix (Table 3 and Fig. 2). The coconut fibres have a maximum tensile strength of $134.3 \pm 34.5 \mathrm{MPa}$ and tensile modulus of $2.16 \pm 0.62 \mathrm{GPa}$. It was also observed that the tensile strength and elastic modulus of the fibres is inversely proportional to the fibre diameter: both properties decrease with increasing fibre diameter (Fig. 2). According to the linear regression analysis,
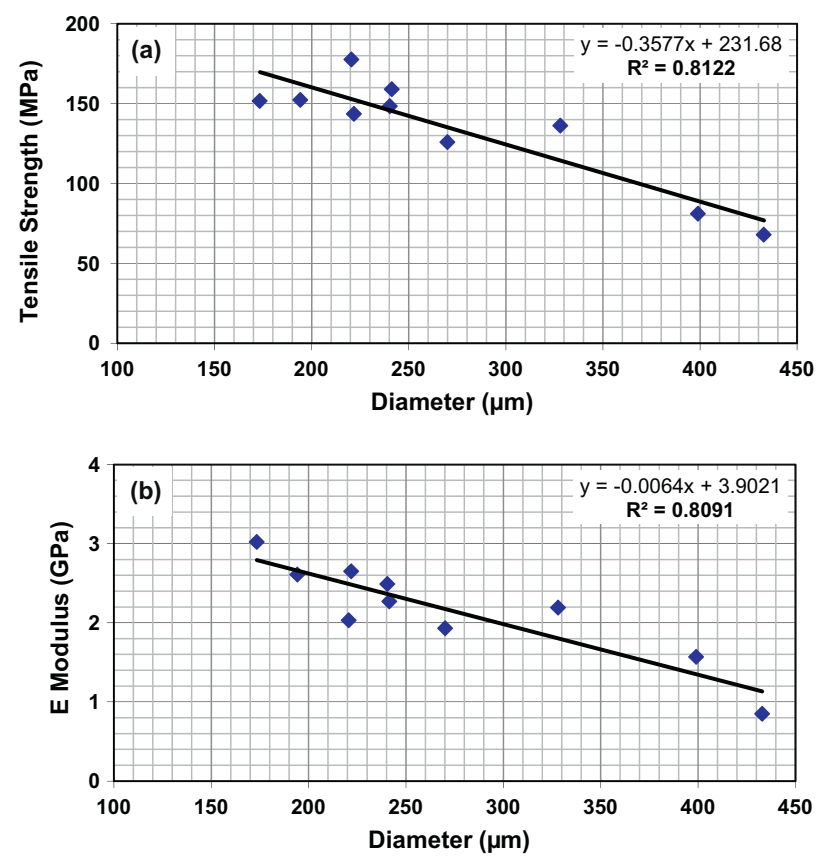

Fig. 2. Mechanical properties of the coconut fibres as a function of the diameter: (a) tensile strength and (b) E modulus. this result was observed for $81 \%$ of the tested fibres. The strain at break for coconut fibres was $34.4 \pm 4.7 \%$. This higher failure strain capacity of the coconut fibres, as compared with other natural fibres, can also contribute for a better strain compatibility between the fibres and the polyethylene matrix, making them and interesting material to be used in short-fibre filled composites.

\subsection{Composite morphology}

Scanning electron microscopy (SEM) is a common method to analyse the level of fibre/matrix interfacial adhesion. The fracture surface morphology, after tensile tests, of the developed composites is shown in Fig. 3. The micrographs of the cork-polymer composite (50-50) wt.\% or CPC 1 composition (Fig. 3b) shows the cork powder cell walls in contact with the polyethylene matrix. This image reveals also a fragile fracture that is the result of the high volume content of cork powder. Moreover, the tensile fracture discloses that the cellular structure of cork powder is maintained but with a more compact morphology after the two processing steps of extrusion and compression moulding, explaining the densification that occurs on the lignocellulosic composites. The fracture surface of the composite prepared with the same cork/PE ratio and reinforced with 10 wt.\% of short coconut fibre (CPC 5) was analysed and the results are shown in Fig. $3 \mathrm{c}$ and d. From these images is possible to conclude that the interfacial adhesion between the fibres and the polymeric matrix is poor. The untreated fibres appear to be free of any matrix material adhering to them. It can be also observed the presence of cavities between the coconut fibre and the cork-polymer components. Additionally, significant coconut fibre breakage was observed during pelletization process after conventional melt mixing, reinforcing the idea of low adhesion between coconut fibres and the thermoplastic matrix. Nevertheless, the addition of $2 \%$ of maleic anhydride produced an opposite effect. The micrographs from the fracture surface of CPC 6 of Fig. 3e and $f$ show a good interfacial adhesion between the coconut fibres (10 wt.\%) and the polymeric matrix. In this last case, the fracture of the coconut fibre occurred preferentially at the same level of the composite fracture. Generally, chemical coupling agents are molecules having two functions [6]: the first is to react with the hydroxyl groups of cork and of cellulosic fibres $(\mathrm{OH}$ groups) and the second is to react with functional groups of the matrix. The expected result is the reduction of these groups that contribute to the hydrophilic character, promoting the compatibility between the matrix and the natural component.

\subsection{Composite mechanical properties}

\subsubsection{Tensile properties and density}

Tensile tests were performed in order to evaluate the efficiency of the envisaged strategy aimed for improving the mechanical performance of the cork-polymer composites (CPCs). Table 4 presents the experimental mean values with the standard deviation, the improvement on the mechanical properties in terms of variation (\%) when compared with the CPC 1 cork-polymer (50-50) wt.\%, the coefficient of variation $\left(C_{\mathrm{v}}\right)$ for each tested group and the density of the composite materials. In addition, Fig. 4 shows the 

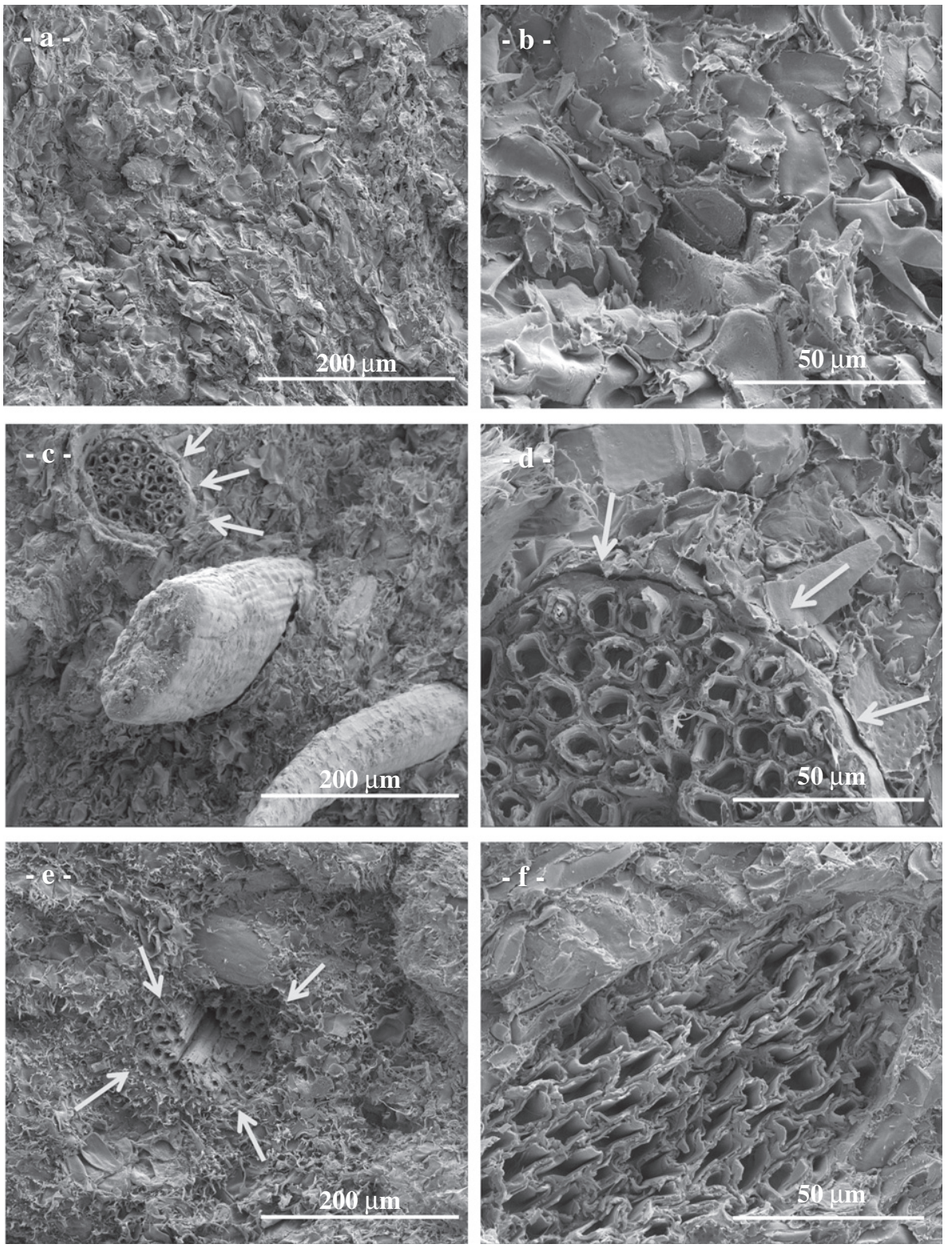

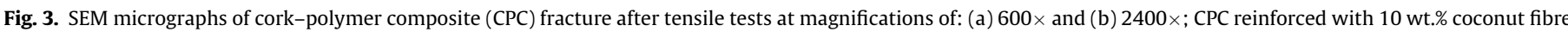
at magnifications of (c) $600 \times$ and (d) $2400 \times$; CPC reinforced with 10 wt.\% coconut fibre with 2 wt.\% of coupling agent at magnifications of (e) $600 \times$ and (f) $2400 \times$.

Table 4

Mechanical properties of the cork-polymer composites reinforced with and without coconut fibres after tensile tests and respective density after two step processing.

\begin{tabular}{|c|c|c|c|c|c|c|c|c|}
\hline Code & $\sigma_{\max }(\mathrm{MPa})$ & Variation (\%) & $C_{\mathrm{v}}(\%)$ & $\mathrm{E} 1 \%(\mathrm{RLin})(\mathrm{MPa})$ & Variation (\%) & $C_{\mathrm{v}}(\%)$ & Deformation max. (\%) & CPC density $\left(\mathrm{kg} / \mathrm{m}^{3}\right)$ \\
\hline CPC 1 & $13.9 \pm 0.8$ & - & 5.39 & $471.0 \pm 15.8$ & - & 3.35 & $4.2 \pm 0.2$ & $1049.2 \pm 2.4$ \\
\hline CPC 2 & $15.7 \pm 0.4$ & 12.5 & 2.08 & $431.8 \pm 24.4$ & -8.3 & 5.65 & $7.2 \pm 0.1$ & $1037.0 \pm 5.4$ \\
\hline $\mathrm{CPC} 3$ & $13.4 \pm 0.3$ & -4.2 & 4.53 & $556.2 \pm 54.3$ & 18.1 & 9.75 & $3.9 \pm 0.2$ & $1058.8 \pm 8.0$ \\
\hline CPC 4 & $17.7 \pm 1.1$ & 26.8 & 6.19 & $488.9 \pm 42.7$ & 3.8 & 8.74 & $5.4 \pm 0.4$ & $1057.5 \pm 2.7$ \\
\hline CPC 5 & $14.2 \pm 0.5$ & 2.0 & 3.79 & $572.9 \pm 44.9$ & 21.6 & 7.84 & $4.5 \pm 0.7$ & $1066.1 \pm 4.4$ \\
\hline CPC 6 & $20.4 \pm 0.3$ & 46.2 & 1.56 & $598.7 \pm 19.5$ & 27.1 & 3.25 & $6.4 \pm 0.4$ & $1061.7 \pm 1.5$ \\
\hline
\end{tabular}

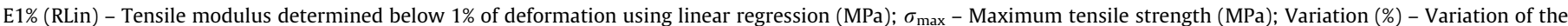
mean value (\%) of the mechanical property comparing with CPC1 (50-50) wt.\% condition; $C_{\mathrm{v}}-$ Coefficient of variation (\%); \pm- Standard deviation.

tensile properties of the developed composites with the statistical relevant differences for a confidence level of $95 \%$.

The density of the cork based composites was in the range between 1032 and $1070 \mathrm{~kg} / \mathrm{m}^{3}$. The presence of $2 \mathrm{wt} . \%$ of coupling agent (CA), promotes a positive effect. This is shown by a slight decrease on the composite density, probably due to a better dispersion of the natural phase on the matrix.
Comparing the CPC 1 and CPC 2 is possible to observe an increase of $12.5 \%$ in the maximum tensile strength promoted by the CA. The results are in accordance with the previous work using different qualities of cork powders with polyolefins processed by pultrusion [14]. When 5-10 wt.\% of short coconut fibres (CPC 3 and CPC 5) were used an increase of $18.1-21.6 \%$ on the tensile modulus was achieve being the hybrid composites stiffer. 
However, no significant differences were observed on maximum strength. Therefore, the use of fibres, without any additional physical or chemical treatment or additive, showed less efficiency than expected from their strength properties (see Table 3 ) due to the poor adhesive interaction between the matrix and coconut fibres. This was reflected on the almost insignificant increase on the tensile strength and reduction on ductility (Table 4). These results are in accordance with the morphological observations. On the other hand, the use of coconut fibres in combination with $2 \mathrm{wt} . \%$ of CA resulted in an significant increase of the tensile properties, independently of the amount of fibres used. These effect was more pronounced when it was used the higher fraction $10 \mathrm{wt} . \%$ of coconut fibre (CPC 6), resulting in an increase of $46 \%$ on maximum strength and $27 \%$ on tensile modulus and higher maximum strain at break when compared with the unreinforced cork-polymer composite (CPC 1). This considerable increment on the tensile properties is justified with the enhancement of the interfacial adhesion between the matrix and the fibres promoted by the CA based on maleic anhydride that improves its ability to transfer stresses across the interface resulting on an increase of the mechanical properties of the final composite. The $C_{\mathrm{v}}$ percentages reported in Table 4 , shows the weight of the standard deviation over the distribution. The maximum and minimum values registered were $6.2 \%$ and $1.6 \%$ for tensile strength and, $9.8 \%$ and $3.3 \%$ for tensile modulus. The lowest $C_{\mathrm{v}}$ values were obtained for the composite with higher mechanical performance (CPC 6). This is a clear indication that the produced boards had low variation on the mechanical properties, supporting the idea of homogeneous hybrid composites with good distribution of the natural component in the matrix.

\subsubsection{Ashby diagram}

The mechanical properties of the different formulations were additionally organized in an Ashby diagram by plotting maximum tensile strength versus tensile modulus of the CPC with the respective both standard deviations (Fig. 5). The results plotted in the graph can be divided in three distinct regions: a first region corresponding to the mechanical properties of the cork based composites with and without the CA (СPC 2 and CPC 1 respectively); a second region corresponding to the composites just reinforces with fibres (CPC 3 and CPC 5); and a third region corresponding to composites reinforced with fibres and treated with maleic anhydride composites with higher tensile strength (CPC 4 and CPC 6). In Fig. 5 the results were also divided just in two regions: a bottom region corresponding to the composites prepared without CA and presenting lowest values of tensile strength but similar tensile modulus; and a top region corresponding to the composites with highest

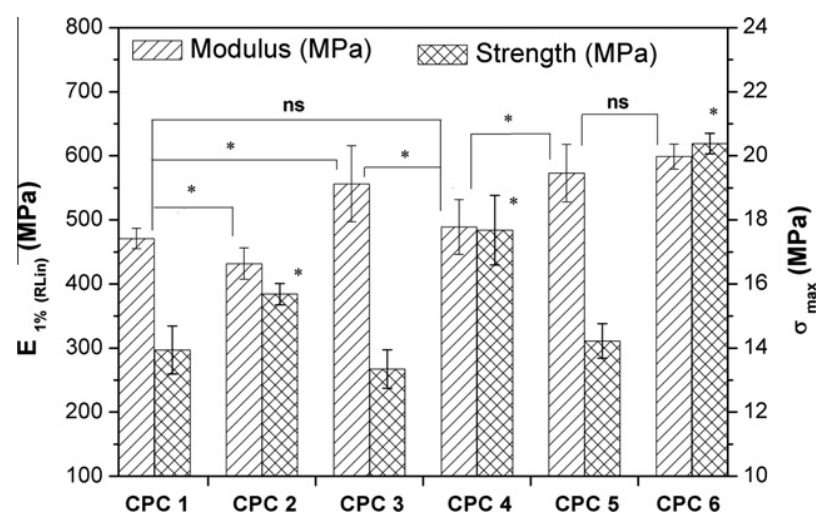

Fig. 4. Mechanical properties of the developed composites. Symbol $(*)$ denote composite materials with statistical significant differences $(p<0.05)$ and (ns) not significant, as using the one-way ANOVA method.

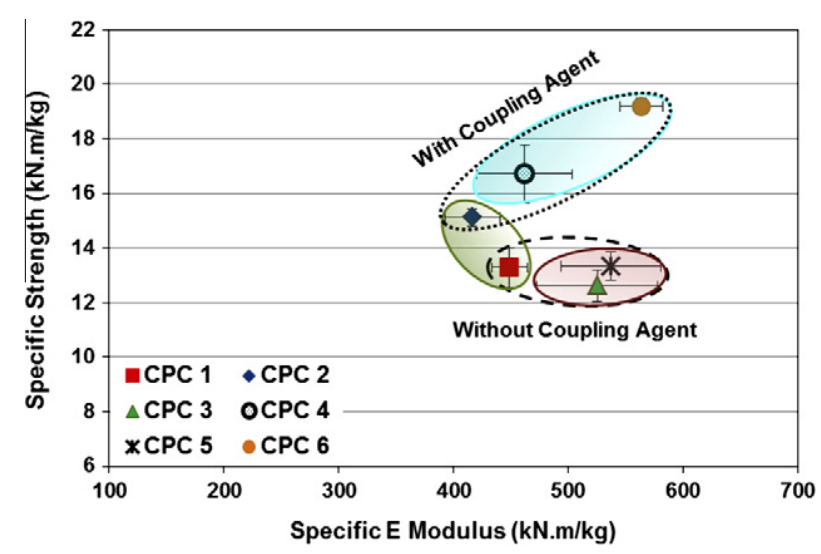

Fig. 5. Ashby plot presenting the specific maximum tensile strength against specific tensile modulus of the cork-polymer composites (CPCs) obtained by extrusion followed by compression moulding.

values of tensile strength and tensile modulus. Interestingly, the diagram highlights the importance of the combine effect of CA based on maleic anhydride and the addition of coconut fibres as reinforcement strategy on cork-polymer composites.

\section{Conclusions}

The mechanical reinforcement strategy of cork powder composites using random discontinuous distributed coconut fibres through melt based technologies was investigated. The morphological observations were in accordance with the mechanical results, showing the improved effect of fibre-matrix adhesion in the presence of 2 wt.\% of coupling agent (CA) based on maleic anhydride. The Ashby diagram supported to identify the best developed composite formulation and to visualize the improvement over the cork powder-polymer (50-50) wt.\% composite. The incorporation of $10 \mathrm{wt} . \%$ of coconut fibre in the presence of $2 \mathrm{wt} . \%$ of CA on the cork-based composites presented an increase of $46 \%$ on the mechanical properties in terms of tensile maximum strength of and $27 \%$ in terms of tensile modulus comparing with the unreinforced cork-polymer composite solution. Additionally, the presence of CA increases the maximum strain values in all processed composites.

The maximum values registered in terms of coefficient of variation for this reinforced cork-based composite solution was 3.3\% for the tensile modulus and $1.6 \%$ for the tensile strength properties. The lower coefficient variation supports the homogeneous properties in terms of short fibre distribution on the novel hybrid corkbased composites. With this strategy it was possible to both improve the mechanical performances of cork-based composites and to increase the natural component up to $54 \mathrm{wt}$.\% on the novel hybrid cork-based composite materials.

\section{Acknowledgments}

The work was performed within the project of Corticeira Amorim S.G.P.S. on the development of new products based in/with cork. We gratefully acknowledge to Amorim Revestimentos S.A. for the supply of cork and to Amorim Isolamentos S.A. for the coconut fibres and to Pallmann $\mathrm{GmbH}$ for the grinding polymer. E.M.F. and V.M.C. acknowledges to Portuguese Foundation for Science and Technology (FCT) grants (SFRH/BD/71561/2010) and (SFRH/BPD/ $64790 / 2009)$ respectively. 


\section{References}

[1] Mohanty AK, Misra M, Hinrichsen G. Biofibres, biodegradable polymers and biocomposites: an overview. Macromol Mater Eng 2000;276(3-4):1-24.

[2] Bledzki AK, Gassan J. Composites reinforced with cellulose based fibres. Prog Polym Sci 1999;24(2):221-74.

[3] $\mathrm{Ku} \mathrm{H}$, Wang $\mathrm{H}$, Pattarachaiyakoop N, Trada M. A review on the tensile properties of natural fiber reinforced polymer composites. Compos Part B Eng 2011;42(4):856-73.

[4] Ayrilmis N, Jarusombuti S, Fueangvivat V, Bauchongkol P, White RH. Coir fiber reinforced polypropylene composite panel for automotive interior applications. Fiber Polym 2011;12(7):919-26.

[5] Fernandes EM, Correlo VM, Chagas JAM, Mano JF, Reis RL. Properties of new cork-polymer composites: advantages and drawbacks as compared with commercially available fibreboard materials. Compos Struct 2011;93(12): 3120-9.

[6] Pandey JK, Ahn SH, Lee CS, Mohanty AK, Misra M. Recent advances in the application of natural fiber based composites. Macromol Mater Eng 2010; 295(11):975-89.

[7] Silva SP, Sabino MA, Fernandes EM, Correlo VM, Boesel LF, Reis RL. Cork: properties, capabilities and applications. Int Mater Rev 2005;50(6):345-65.

[8] Gibson LJ, Easterling KE, Ashby MF. The structure and mechanics of cork. Proc Roy Soc Lond A Mat 1981;(A377): 99-117.

[9] Gil L. Cork composites: a review. Mater Des 2009;2(3):776-89.

[10] Fernandes EM, Silva VM, Chagas JAM, Reis RL. Fibre-reinforced cork-based composites. WO2011014085-A2, Amorim Revestimentos. SA; 2011.

[11] Westerlind BS, Berg JC. Surface-energy of untreated and surface-modified cellulose fibers. J Appl Polym Sci 1988;36(3):523-34.

[12] Barlow CY, Ashby MF. Cork dust composites. In: Proceedings of the Riso international symposium on metallurgy and materials science; 1989. p. 27581.

[13] Moresco M, Leal Rosa SM, Santos EF, Bohrz Nachtigall SM. Agrofillers in polypropylene composites: a relationship between the density and the mechanical properties. J Appl Polym Sci 2010; 117(1): 400-8.

[14] Fernandes EM, Correlo VM, Chagas JAM, Mano JF, Reis RL. Cork based composites using polyolefin's as matrix: morphology and mechanical performance. Compos Sci Technol 2010;70(16):2310-8.
[15] Abdallah FB, Cheikh RB, Baklouti M, Denchev Z, Cunha AM. Effect of surface treatment in cork reinforced composites. J Polym Res 2009;17(4): 519-28.

[16] Wei W, Gu H. Characterisation and utilization of natural coconut fibres composites. Mater Des 2009;30(7):2741-4.

[17] Bledzki AK, Reihmane S, Gassan J. Properties and modification methods for vegetable fibers for natural fiber composites. J Appl Polym Sci 1996;59(8): 1329-36.

[18] Bilba K, Arsene M-A, Ouensanga A. Study of banana and coconut fibers botanical composition, thermal degradation and textural observations. Bioresour Technol 2007;98(1):58-68.

[19] Pereira H. Chemical composition and variability of cork from Quercus suber L. Wood Sci Technol 1988;22(3):211-8.

[20] Faruk O, Bledzki AK, Fink H-P, Sain M. Biocomposites reinforced with natura fibers: 2000-2010. Prog Polym Sci 2012;37(11):1552-96.

[21] Rozman HD, Tay GS, Kumar RN, Abubakar A, Ismail H, Ishak ZAM Polypropylene hybrid composites: a preliminary study on the use of glass and coconut fiber as reinforcements in polypropylene composites. Polym-Plast Technol 1999;38(5):997-1011.

[22] Brahmakumar M, Pavithran C, Pillai RM. Coconut fibre reinforced polyethylene composites: effect of natural waxy surface layer of the fibre on fibre/matrix interfacial bonding and strength of composites. Compos Sci Technol 2005; 65(3-4):563-9.

[23] Wambua P, Ivens J, Verpoest I. Natural fibres: can they replace glass in fibre reinforced plastics? Compos Sci Technol 2003;63(9):1259-64.

[24] Sampathrajan A, Vijayaraghavan NC, Swaminathan KR. Mechanical and thermal-properties of particle boards made from farm residues. Bioresour Technol 1992;40(3):249-51.

[25] Lamazere JHA. Building boards from coconut husks using ground coconut shell filter with cement, sand and water for thermal and acoustic insulation. FR2666327-A1, Lamazere JHA; 1992.

[26] Bismarck A, Mohanty AK, Aranberri-Askargorta I, Czapla S, Misra M Hinrichsen G, et al. Surface characterization of natural fibers; surface properties and the water up-take behavior of modified sisal and coir fibers. Green Chem 2001;3(2):100-7. 